\title{
Autoamputation of Fingers - A Rare Presentation of Tethered Cord after Early Repair of Cervicothoracic Myelomeningocele
}

\author{
Venkata Ramesh Chandra Vemula ${ }^{1}$ Chandramowliswara Prasad Bodapati ${ }^{1}$ Jayachandar Vuttarkar ${ }^{1}$ \\ Sanjeev Akula ${ }^{1}$ Krishnamohan Chennati ${ }^{1}$ \\ ${ }^{1}$ Department of Neurosurgery, Sri Venkateswara Institute of Medical \\ Sciences, Tirupati, Andhra Pradesh, India \\ Indian J Neurosurg 2017;6:76-78.

\begin{abstract}
Address for correspondence Venkata Ramesh Chandra Vemula, MCh Department of Neurosurgery, Sri Venkateswara Institute of Medical Sciences, Tirupati, Andhra Pradesh 517507, India (e-mail: rcvvns@gmail.com).
\end{abstract}

\begin{abstract}
Keywords

- tethered cord

- myelomeningocele findings are discussed.

\section{Introduction}

Spinal dysraphism occurs infrequently in the cervicodorsal region and the frequency varies, with occult spinal dysraphism $(1.6 \%)^{1}$ and spina bifida cystica (3.9-8\%). ${ }^{2,3}$ Approximately 3 to $5 \%$ of children will develop secondary tethered cord syndrome (TCS) following repair of a myelomeningocele and most commonly occur in the lumbosacral region. ${ }^{4}$ Self-mutilation of the fingers due to concurrent secondary tethering of the cord is very rare and only one such case has been reported in literature. ${ }^{5}$ We report a case of secondary tethered cord presenting with self-mutilation of the fingers managed surgically with good results.
\end{abstract}

Dorsal myelomeningoceles are rare but well-recognized lesions. The phenomenon of the cord tethering at the operative site several years after surgery is known. Selfmutilation of the fingers as the presenting symptom of such tethered cord is extremely rare with only one case reported in literature. We report a 14-year-old girl with past history of undergoing dorsal myelomeningocele repair at birth presenting with history of nonhealing ulcer at the proximal phalanx of the little finger and the absence of the middle and distal phalanges. Imaging revealed tethering of the cord at the previous surgical site. She underwent exploration of the surgical site and detethering of the cord yielding good results. The clinical, radiological, and operative

\section{Case History}

A 14-year-old girl presented with history of nonhealing ulcer and loss of distal and middle phalanges of her left little finger. She had undergone repair of myelomeningocele at D1 to D3 level in her childhood. She was asymptomatic until 11 years of age when she noticed gradual onset of decreased sensations to all modalities in her left hand especially the ring and little finger. She had dysesthesias in her little finger and to get relief she used to graze it against a rough surface. This self-mutilation led to gradual loss of tissue and a nonhealing chronic ulcer on her little finger. On examination, there were trophic changes involving left hand with a nonhealing ulcer of the little finger and loss of phalanges of ring and little fingers ( $\mathbf{F i g}$. 1A).There was loss of sensation to all modalities of the little finger. There was no weakness of any group of muscles but had grade 1 spasticity of the lower limbs with bilateral extensor plantar response. There was no history suggestive of bowel or bladder involvement. Magnetic resonance imaging (MRI) of the dorsal spine revealed tethering of the cord at D1-D3 levels (previous surgical site) with focal syringomyelia (-Fig. 2A).With a diagnosis of secondary tethered cord syndrome she was taken up for surgery. The previous operative site was explored through a midline incision from C6 to D5. Laminectomy of C7 and D4 was done to expose the normal dural tube. All the adhesions along D1 to D3 were removed and received

May 3, 2016

accepted

June 1, 2016

published online

October 25, 2016
DOI http://dx.doi.org/

$10.1055 / \mathrm{s}-0036-1588034$ ISSN 2277-954X.
License terms

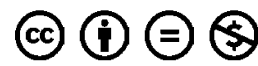

(c) 2017 Neurological Surgeons' Society
of India 


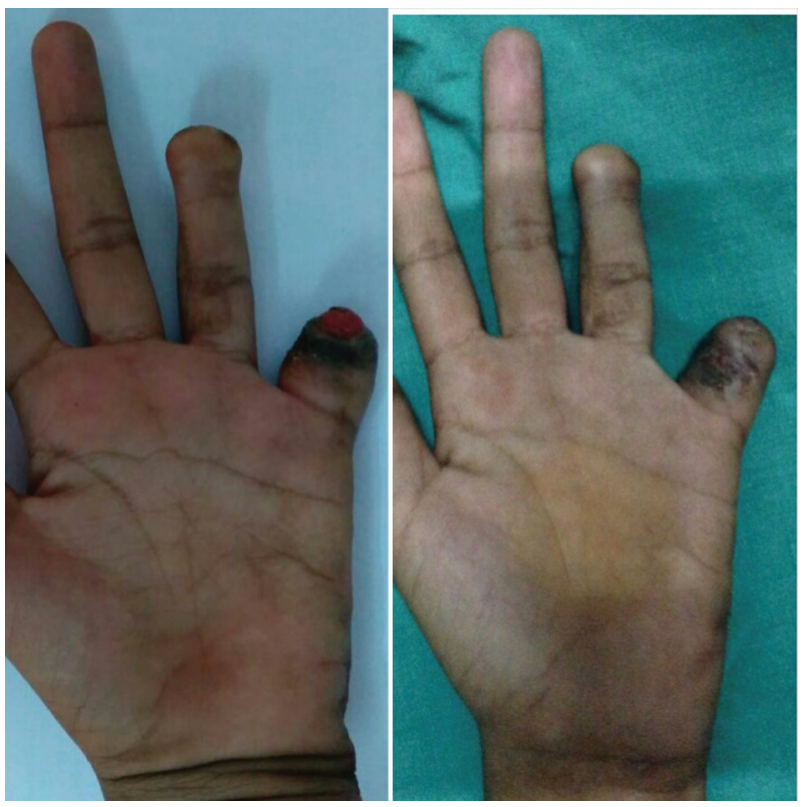

Fig.1 Preoperative (A) and postoperative (B) clinical photo of the left hand showing trophic changes, loss of distal phalanx of the ring finger, loss of distal and middle phalanges of the little finger, and nonhealing ulcer with granulation involving the little finger which healed postoperatively.

the dura was opened at $\mathrm{C} 7$ level under operating microscope. The dural opening was extended around the scar tissue and tethered cord segment till D4 level. The tethered cord was meticulously dissected from the scar tissue and the dura was closed primarily. The postoperative period was uneventful. At 6 months follow-up she had improvement in the sensations of her left hand and the ulcer slowly healed ( - Fig. 1B).The followup MRI showed improved alignment of the spinal cord and loss of tethering (-Fig. 2B)

\section{Discussion}

Secondary TCS following repair of a myelomeningocele is a well-recognized but under-reported entity. ${ }^{5}$ The incidence of symptomatic tethered cord after myelomeningocele reported in literature ranges from 3 to $30 \%{ }^{4,6}$ The onset of symptoms due to secondary tethering may start anytime between early childhood and late adulthood ${ }^{7}$ but most commonly present at an age of 2 to 8 years. ${ }^{6}$ The major clinical presentations of secondary TCS are increased weakness, gait abnormalities, scoliosis, pain, orthopedic deformities, and decreased urological function. ${ }^{8}$ Self-mutilation in the form of tongue biting, mutilation of the lips, and fingertips, suggests analgesia resulting from abnormalities of the sensory systems. It is seen in several conditions including the hereditary sensory and autonomic neuropathies (I-V), Lesch-Nyhan syndrome, chronic juvenile rheumatoid arthritis, pyridoxine intoxication, brachial plexus injury in infants, and spinal cord injuries in children. ${ }^{9}$ Tethered cord presenting as self-mutilation of the fingers is very rare and only two cases are reported in literature. Myles et al reported self-mutilation of the fingers in a 1-year-old girl

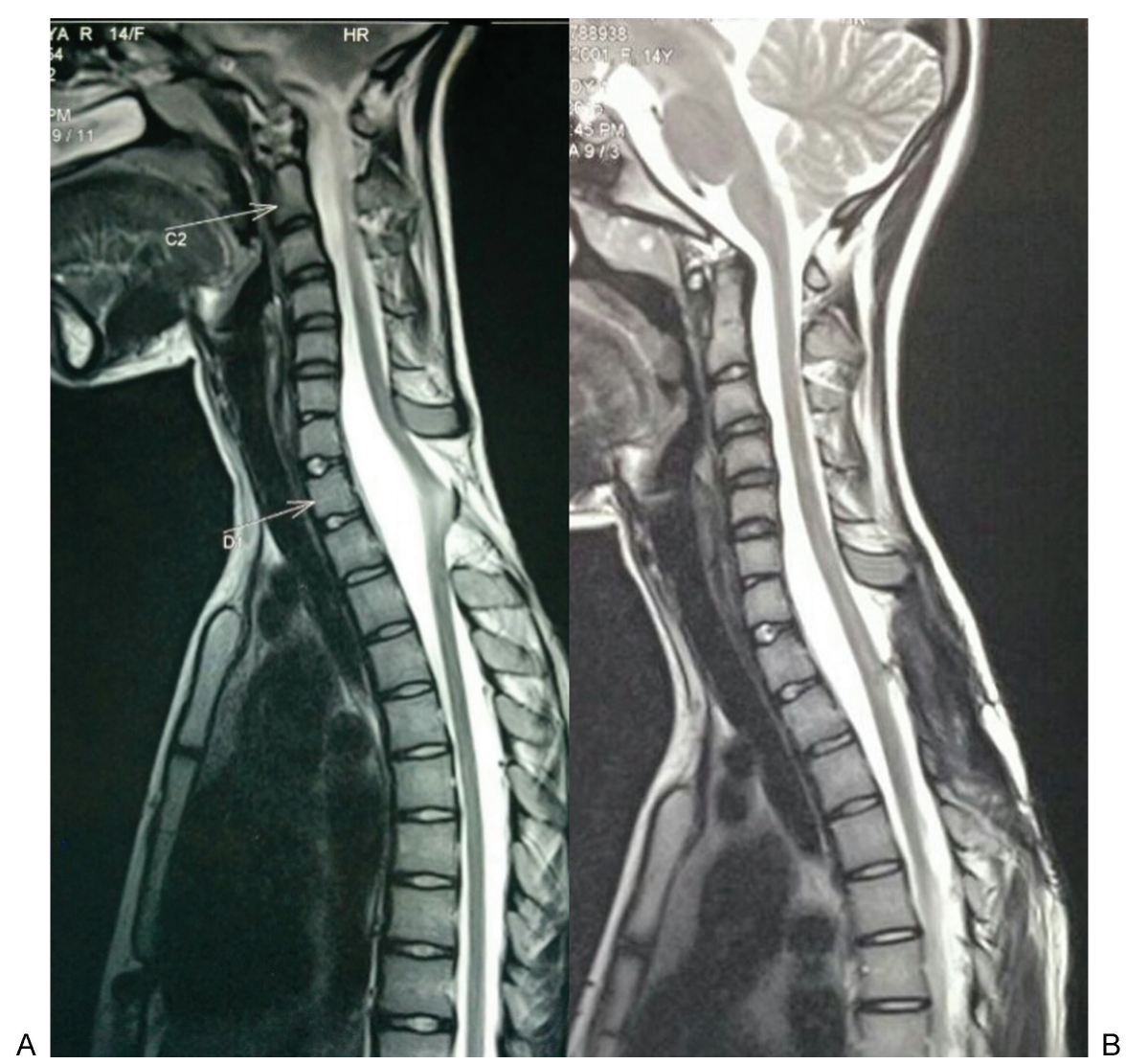

Fig. 2 Magnetic resonance imaging of the cervicodorsal spine T2-weighted saggital preoperative (A) and postoperative (B) showing the tethering of the cord at D1-D2 levels with localized syrinx formation with resolution following surgery. 
with occult spinal dysraphism. The mechanism of selfmutilation injury in this patient was by repeated trauma from sucking and biting the fingers in the presence of abnormal sensory pathways from cord damage. ${ }^{9}$ Tubbs et al reported a 16-year-old girl who was born with a myelomeningocele and noted that concurrent with her spinal cord becoming symptomatically tethered, she began to self-mutilate her digits. The mechanism of self-mutilation may be the dysesthesias secondary to the tethering of the cord. ${ }^{5}$ The case reported by us is similar to that of Tubbs et al and a similar mechanism can explain the self-mutilation of the fingers. The response to surgical intervention in both the cases was good with healing of the wounds and good neurological recovery similar to our patient. Pathophysiology of TCS relates to the restricted normal movements of the spinal cord that would occur with flexion, extension, and axial growth of the spine causing stretching of the lower aspect of the spinal cord and resultant injury. ${ }^{10}$ The primary goal of surgical correction is to release the spinal cord from the adhering scar most commonly located in the area of the previous closure. Additional abnormalities are found in $30 \%$ of the cases and they should be looked for and addressed. ${ }^{8}$ The outcome is particularly good in relation to pain and weakness, but the procedure is not as successful in alleviating sphincter dysfunction. ${ }^{9}$

\section{Conclusion}

Self-mutilation of the fingers is a very rare presentation of tethered cord and should be suspected in a patient with new onset neurological symptoms following myelomeningocele repair.

\section{Disclosure}

None.

Acknowledgment

None.

\section{References}

1 Schiffer J, Till K. Spinal dysraphism in the cervical and dorsal regions in childhood. Childs Brain 1982;9(2):73-84

2 Fisher RG, Uihlein A, Keith HM. Spina bifida and cranium bifidum: study of 530 cases. Proc Staff Meet Mayo Clin 1952; 27(2):33-38

3 Doran PA, Guthkelch AN. Studies in spina bifida cystica. I. General survey and reassessment of the problem. J Neurol Neurosurg Psychiatry 1961;24:331-345

4 Tamaki N, Shirataki K, Kojima N, Shouse Y, Matsumoto S. Tethered cord syndrome of delayed onset following repair of myelomeningocele. J Neurosurg 1988;69(3):393-398

5 Tubbs RS, Oakes WJ. Self-mutilation in a child with a tethered spinal cord. Case report. J Neurosurg 2005;102(2, Suppl)228-230

6 Hudgins RJ, Gilreath CL. Tethered spinal cord following repair of myelomeningocele. Neurosurg Focus 2004;16(2):E7

7 Wilden JN, Hadley D. Delayed tethered cord syndrome after myelomeningocele repair. J Neurosurg 1989;70(5):815-816

8 Herman JM, McLone DG, Storrs BB, Dauser RC. Analysis of 153 patients with myelomeningocele or spinal lipoma reoperated upon for a tethered cord. Presentation, management and outcome. Pediatr Neurosurg 1993;19(5):243-249

9 Myles LM, Steers AJ, Minns R. Cervical cord tethering due to split cord malformation at the cervico-dorsal junction presenting with self-mutilation of the fingers. Dev Med Child Neurol 2002; 44(12):844-848

10 Yamada S, Zinke DE, Sanders D. Pathophysiology of "tethered cord syndrome". J Neurosurg 1981;54(4):494-503 